poco entretenida, es la sección que reúne las numerosas fómunulas usadas entre enamorados: "amor, amorcito, mi amoi, mi amorcito, mijo, mija, santo, santa, mi santo, mi santa, vida", etc. seguidas de ejemplos en frases como ésta: "Amor, ¿cómo estás?" Podria argumentarse que estos tratamientos no por obvios son superfluos; dc hecho se explora un sinnúmero de posibilidades entre las que cncontramos la sección "Tratamientos eclesiásticos" con las subdivisiones "A sacerdotes y frailes" y "Entre las religiosas" (p. 137). Pero mientras hay cinco páginas de hipocorísticos, en la sección "Piropos y tratamientos callejeros" se omiten voces populares diciendo: "A veces se llega a la grosería, pero nos vamos a detener en las formas más urbanas" (p. 135).

En el segundo capítulo, "Las fórmulas del coloquio", la gran mayoría de las expresiones que se discuten pertenece al español general. Los intentos de clasificación por regiones se ven frustrados ya que la auto$\mathrm{ra}$, si bien insiste en dar la extensión del fenómeno, en muchas ocasiones lo documenta como sigue: “ $E$ Epa! se usa mucho en Caracas, Lara, Yaracuy, los Llanos, etc." El tercer capitulo, "Eufemismos, disfemismos y expresiones figuradas", explora la creación idiomática de los venezolanos y es riquísimo en cuanto acopio de formas. La sección sobre la muerte es particularmente interesante por las correspondencias que se pueden encontrar con México (cf. J. Lope Blanch, Vocabulario mexicano relativo a la muerte). En última instancia, éste pretende ser un libro de consulta al que acudirá el dialectólogo para documentarse en cuestiones de uso para Venezuela. Sin embargo la falta de rigor lingüistico en el tratamiento de las formas, obliga a relegar este estudio a la categoría de útil pero sin relieve.

\title{
Giorgio Perissinotto
}

State University of New York

at Stony Brook.

Humberto López Morales, Estudio sobre el español de Cuba. Las Americas Publishing Co., New York, 1971; 188 pp.

El autor reunió bajo este título una serie de artículos, algunos de ellos publicados anteriormente ${ }^{1}$; quizá esta sea la causa de la poca homogeneidad del libro, que el mismo autor advierte. Los cuatro primeros capítulos se dedican a ciertos problemas léxicos; por ejemplo, el establecimiento de una "nómina pasiva": de indigenismos y afrone-

1 "Observaciones fonéticas sobre la lengua de la poesía afrocubana" fue publicado anteriormente con el título de "La lengua de la poesía afrocubana", $E A c, 7$ (1966), 1-3; "Neutralizaciones fonológicas en el consonantismo final del español de Cuba", ALM, 5 (1965), 183-190; "Nuevos datos sobre el roseo en Cuba", EAC, 4 (1967), 4-6; "El español de Cuba: situación bibliográfica", originalmente fue una ponencia presentada al V Congreso del PILEI, São Paulo, 1969.

2 Las voces que constituyen la "nómina pasiva" son formas integrantes del paradigma, independientemente de su realización; a diferencia de las voces de la "nómina activa", que son las que se recogen del habla. 
grismos, frente a una "nómina activa" de estos mismos elementos y de algunos anglicismos; se analizan también algunos regionalismos. Los tres siguientes capítulos se ocupan de problemas de carácter fonético: la posible influencia africana en la fonética cubana, la realización de fonemas fricativos no aspirados y la neutralización de consonantes. El octavo capítulo, de enfoque morfológico, se refiere al voseo en el habla del oriente de Cuba. Finalmente se reseñan los estudios lingüísticos que se han hecho en Cuba desde 1868 hasta 1968.

En el estudio de indigenismos y afronegrismos, López Morales construye una nómina hipotética extraída del Diccionario de Pichardo ${ }^{3}$ y de los materiales de Buesa Oliver ${ }^{4}$ para los indigenismos, y del Glosario de afronegrismos ${ }^{\bar{j}}$ para los elementos africanos. Este corpus se presentó a cada uno de los cincuenta informantes de las diferentes provincias de Cuba. Para formar la "nómina pasiva" cada elemento tenía que ser identificado por más del cincuenta por ciento de los informantes, y debía ser definido mediante un mínimo de dos semas; esto último constituye un acierto en la metodología de encuestas léxicas porque permite eliminar respuestas vagas. En esta nómina pasiva se recogieron noventa y siete indigenismos y cuarenta afronegrismos.

Para establecer la "nómina activa" de indigenismos, afronegrismos y anglicismos se trabajó sobre la base de dos corpus confeccionados por el PILEI; uno constituido por las respuestas a un cuestionario dividido en veintiún áreas léxicas, y el otro por los materiales recolectados en trescientas ochenta horas de grabación magnetofónica del habla de La Habana. Tales materiales representaron una reducción sintópica (La Habana) y sinestrática (habla culta); a causa de esto el autor advierte sobre el carácter limitado de sus conclusiones. En esta nómina se da el porcentaje de la frecuencia de indigenismos, afronegrismos y anglicismos. Al comparar los resultados obtenidos en los dos corpus se advierte en el segundo (diálogos espontáneos) una notable disminución en la frecuencia tanto de indigenismos como de afronegrismos y anglicismos; esto se explica porque en el recuento se incluyeron palabras gramaticales por ser el resultado de una encuesta libre. Se añade un cuadro en el que están distribuidos los indigenismos según la lengua de la cual proceden (p. 6l). Sorprende el encabezado de este cuadro: "indigenismos según el origen dialectal", lo cual implicaría preguntarse si el autor considera dialecto como sinónimo de "lengua indigena".

Los regionalismos, estudiados en el capítulo 4, provienen solamente de los vocabularios que aparecen en dos textos: Viaje de Perico Ligero al pais de los moros (1816) y Cuadro estadistico de la siempre fiel isla de Cuba (1827).

En cuanto a las investigaciones fonéticas, analiza en un capítulo los trabajos que se han hecho sobre algunas características fonéticas de la poesía negra. López Morales confronta las conclusiones de estos estu-

3 Esteban Pichardo, Diccionario provincial de voces cubanas. Matanzas, 1836.

4 Tomás Buesa Oliver, Indoamericanismos léxicos en español, C.S.I.C., Madrid, $196 \tilde{z}$.

5 Frrnando Ortiz, Glosario de afronegrismos, La Habana, 1924. 
dios con las características fonéticas actuales de La Habana y hace notar que los fenómenos considerados como característicos del habla de los negros no son exclusivos ni siquiera del habla cubana en general, sino que muchos de ellos se realizan en otras zonas americanas y aun peninsulares; por lo tanto desecha la hipótesis de una influencia africana en la fonética del español cubano.

En los otros dos capítulos dedicados a problemas fonéticos (realizaciones de fricativas y neutralizaciones) analiza además materiales desde un punto de vista sincrónico; pero no da mayor detalle sobre la metodologia empleada para la recopilación de los datos.

En cuanto a las fricativas no aspiradas, concluye que la norma cubana parece caracterizarse por una tendencia a la distensión articulatoria extrema $a^{6}$ y por la eliminación de articulaciones fricativas posteriores; encuentra también que para el fonema /s/, parece predominar Ia realización fricativa predorsodentoalveolar convexa sorda. El español popular de Cuba presenta las mismas neutralizaciones condicionadas que se dan en el español general, exceptuando, como es de suponer, aquéllas en las que interviene el fonema $/ \theta /$. Cuando analiza la neutralización de la oposición $s / r$, en la realización [fi] (aspiración sono$\mathrm{ra}$ ), alófono tanto del fonema $/ \mathrm{s} /$ como del fonema $/ \mathrm{r} /$, [beflo] veslo y [beflo] verlo, López Morales propone el término archialófono que define como "unidad de neutralización [...] basada en los rasgos de una determinada variante y no en los de las realizaciones fonéticas normales de un fonema" (p. 134).

En el estudio sobre el voseo trabaja con los datos recogidos por diferentes autores, desde Pichardo hasta Rona, quienes señalan a la parte oriental de la isla como región de voseo, o por lo menos con "restos de voseo". Los materiales aportados por el autor, provenientes de cuestionarios y diálogos espontáneos realizados en esa región de Cuba, no registran ningún caso de voseo, lo que hace pensar que éste ha desaparecido en las "regiones clásicas". Sin embargo, López Morales prefiere estudiar otras zonas del territorio cubano antes de dar resultados definitivos sobre el supuesto voseo cubano.

El último capítulo responde a la preocupación del autor por "lo disperso e insuficiente de la información bibliográfica sobre el español de Cuba" (p. 48); es una revisión de los estudios lingüísticos que se hicieron en la isla entre 1868 y 1968 , muy útil para que los interesados en este tema sepan cómo han de manejarlos y qué es lo que pueden esperar de ellos.

Las aportaciones del libro no son definitivas. Tenemos que considerarlo más bien como una guía donde el investigador encontrará algunos puntos de partida para su trabajo.

Josefina García Fajardo

El Colegio de México.

B Llama "cuasifricativas" a las realizaciones en las que la cavidad bucal queda muy abierta y se produce una fricación mínima. 